\title{
The extent of B-form structure in a 6S RNA variant that mimics DNA to bind to the Escherichia coli RNA Polymerase
}

\author{
Nilesh K. Banavali ${ }^{1,2, *}$ \\ 1: Laboratory of Computational and Structural Biology \\ Division of Genetics, Wadsworth Center, NYS Department of Health \\ 2: Department of Biomedical Sciences, School of Public Health \\ State University of New York at Albany \\ email: nilesh.banavali@health.ny.gov \\ Biggs Laboratory, Wadsworth Center, NYS Department of Health, Empire State Plaza, \\ PO Box 509 Albany, NY 12201-0509
}

Tel: 518-474-0569

Fax: 518-474-3181

Website: http://www.wadsworth.org/resnres/bios/banavali.htm 


\section{Abstract}

In a recent article by Darst and coworkers, it was found that a non-coding 65 RNA variant regulates a bacterial RNA polymerase by mimicking B-Form DNA, and a few different nucleic acid duplex parameters were analyzed to understand the extent of B-form RNA structure. In this manuscript, a different structural analysis based on conformational distance from canonical A-form and B-form single-strand structures is presented. This analysis addresses the occurrence and extent of both local and global B-form structure in the published 6S RNA variant model. 
In a recent article describing the structure of non-coding 6S RNA variant bound to an RNA polymerase holoenzyme, Darst and coworkers describe an overall RNA architecture that partially mimics B-form DNA. ${ }^{1}$ In their 3.8 A single particle cryo-EM structure, they show an average major groove width resembling the Bform, and an average minor groove width resembling the A-form, in the duplex regions of the 6S RNA variant (termed 6S RNA* henceforth) that are long enough to measure groove widths. They also show the pitch and rise parameter values to be nearer those for the B-form, while the sugar pucker, phosphate-phosphate distances, and twist parameter values to be nearer those for the A-form. This analysis of nucleic acid duplex parameters shows that the 6S RNA structure has features of both A-form and B-form architectures.

Proximity to A-form and B-form reference structures can also be assessed using a Root Mean Square Deviation (RMSD) measure, ${ }^{2}$ and we have performed such analysis on known RNA crystal structure conformations of $3 \AA$ or greater resolution at the individual single strand dinucleotide (SSD) level. ${ }^{3}$ This analysis does not require duplex structures, and can assess relative proximity to A- and B-form structures at a local or global level. We showed that RNA SSDs approach a B-form structure in many instances, ${ }^{3}$ and this local B-form structure seems to be achieved through both $\mathrm{C}^{\prime}$-endo sugar conformations or base stacking patterns that resemble B-form DNA stacking. ${ }^{4}$ Interestingly, the base RMSD values show a greater propensity for B-form structures than the sugar-phosphate backbone at the SSD level, which suggests an under-representation of B-form-like sugar-phosphate conformations for RNA in the PDB models. While duplex RNA usually adopts an A-form structure with its furanose sugars assuming $\mathrm{C}^{\prime}$-endo pucker conformations, ${ }^{5}$ the $\mathrm{C} 2^{\prime}$-endo pucker is present in some functional RNA motifs, and may possibly be implicated in RNA folding. ${ }^{6,7}$

It is possible to apply such RMSD analysis to understand the extent of local and global B-form conformations in the $6 S$ RNA* $^{*}$ structure (PDB ID: 5VT0, Chain R). Figure $1 \mathrm{~A}$ shows the scatter plot of each $6 \mathrm{~S}$ $\mathrm{RNA}^{*}$ SSD conformation in 2D RMSD space for all, base, and backbone non-hydrogen atoms, with the RMSD values computed with respect to canonical A- and B-form SSD reference structures. These RMSD values are normalized by the RMSD difference between the A- and B-form SSD structures, thus setting the RMSD between the A- and B-forms to a value of 1.0, irrespective of the SSD sequence. The interpolation line between the A- and B-forms is shown as a dotted blue line. The dividing solid red line separates 
the conformational space into two regions, one nearer to the B-form (bordered by a dotted cyan line), and another closer to the A-form (bordered by a dotted pink line). If all SSDs are simply separated into ones relatively closer to the A-form or the B-form, then a majority of the SSDs are clustered near the canonical A-form, but some SSDs clearly cross over to the B-form, mostly in conformational regions further away from the canonical B-form. This behavior was also observed in our larger crystallographic survey, ${ }^{3}$ such that crossing over to the B-form region seems to be easier for RNA if it moves away from both canonical forms, and the region very close to the canonical B-form structure does not seem to be accessible.

To see which SSDs of the $6 S$ RNA* structure might assume a B-form conformation reasonably close to the canonical B-form, a normalized RMSD cutoff was used to limit the distance from the interpolation line (1.0 in this case, shown as a green dotted line). The conformations with base non-hydrogen atom RMSD values that fall in the B-form region within this cutoff distance are shown in red in Figure 1B. This analysis shows that, even for the base moieties more likely to show B-form conformations, there are only six B-form SSD conformations distributed throughout the entire RNA structure that are nearer the canonical B-form. To assess the A-form or B-form proximity for longer stretches of the RNA strands, the single stranded segments that had continuous stacking were identified. These stretches consisted of residues $32-42,43-47,58-68$, 72-81, 83-85, 99-107, 112-134, 137-142, and 144-153. The RMSD values for different components of these single stranded regions are listed in Table 1. The stacked single strand segments showing greater proximity to the B-form than the A-form at these longer length scales (for the base non-hydrogen atoms) are shown in red in Figure 1C. It can be seen that a substantial part of the 6S RNA variant structure assumes overall single stranded conformations that resemble the B-form more than the A-form.

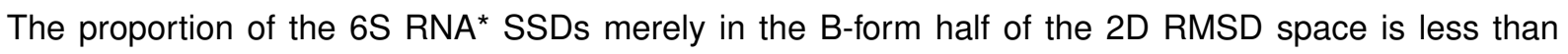
$35 \%$ of the structure, while that closer to the canonical B-form is about $5 \%$ of the structure. In contrast, the proportion of SSDs merely in the A-form half $(68 \%)$ is similar to the proportion close to the canonical A-form $(60 \%)$. This suggests that the $6 \mathrm{~S} \mathrm{RNA}^{*}$ can mimic DNA by having only a third of its SSDs resembling the B-form more than the A-form, and only a twentieth of its SSDs being nearer the canonical B-form structure. The propensity of B-form structure in RNA crystal structure SSD conformations that we assessed previously using the base non-hydrogen RMSD is also near $5 \% .{ }^{3}$ This $6 \mathrm{~S} \mathrm{RNA}^{*}$ structure therefore suggests that RNA 
bioRxiv preprint doi: https://doi org/10.1101/242503; this version posted January 4, 2018. The copyright holder for this preprint (which was not certified by peer review) is the author/funder, who has granted bioRxiv a license to display the preprint in perpetuity. It is made available under aCC-BY-NC-ND 4.0 International license.

may be able to mimic DNA functionally by crossing over into the B-form 2D RMSD space, even through just a substantial minority of its SSDs assuming conformations closer to the B-form than the A-form. 


\section{References}

[1] Chen, J.; Wassarman, K. M.; Feng, S.; Leon, K.; Feklistov, A.; Winkelman, J. T.; Li, Z.; Walz, T.; Campbell, E. A.; Darst, S. A. 6S RNA Mimics B-Form DNA to Regulate Escherichia coli RNA Polymerase. Molecular Cell 2017, 68, 388-397.

[2] Banavali, N. K.; Roux, B. Free energy landscape of A-DNA to B-DNA conversion in aqueous solution. Journal of the American Chemical Society 2005, 127, 6866-6876.

[3] Sedova, A.; Banavali, N. K. RNA approaches the B-form in stacked single strand dinucleotide contexts. Biopolymers 2016, 105, 65-82.

[4] Sedova, A.; Banavali, N. K. Geometric Patterns for Neighboring Bases Near the Stacked State in Nucleic Acid Strands. Biochemistry 2017, 56, 1426-1443.

[5] Fuller, W.; Hutchinson, F.; Spencer, M.; Wilkins, M. Molecular and crystal structures of double-helical RNA: I. An X-ray diffraction study of fragmented yeast RNA and a preliminary double-helical RNA model. Journal of Molecular Biology 1967, 27, 507-524.

[6] Gherghe, C. M.; Mortimer, S. A.; Krahn, J. M.; Thompson, N. L.; Weeks, K. M. Slow conformational dynamics at C2'endo nucleotides in RNA. Journal of the American Chemical Society 2008, 130, 88848885.

[7] Mortimer, S. A.; Weeks, K. M. C2ะendo nucleotides as molecular timers suggested by the folding of an RNA domain. Proceedings of the National Academy of Sciences 2009, 106, 15622-15627.

[8] Kabsch, W. A discussion of the solution for the best rotation to relate two sets of vectors. Acta Crystallographica Section A: Crystal Physics, Diffraction, Theoretical and General Crystallography 1978, 34, 827-828. 
bioRxiv preprint doi: https://doi.org/10.1101/242503; this version posted January 4, 2018. The copyright holder for this preprint (which was not certified by peer review) is the author/funder, who has granted bioRxiv a license to display the preprint in perpetuity. It is made available under aCC-BY-NC-ND 4.0 International license.

Table 1: Canonical form proximity of stacked single strand segments of the 6S RNA variant structure.

\begin{tabular}{cccccccccc}
\hline Residues & $\begin{array}{c}D_{R M S D} \\
\text { All }\end{array}$ & $\begin{array}{c}D_{R M S D} \\
\text { Base }\end{array}$ & $\begin{array}{c}D_{R M S D} \\
\text { Backbone }\end{array}$ & $\begin{array}{c}R M S D_{A} \\
\text { All }\end{array}$ & $\begin{array}{c}R M S D_{B} \\
\text { All }\end{array}$ & $\begin{array}{c}R M S D_{A} \\
\text { Base }\end{array}$ & $\begin{array}{c}R M S D_{B} \\
\text { Base }\end{array}$ & $\begin{array}{c}R M S D_{A} \\
\text { Backbone }\end{array}$ & $\begin{array}{c}R M S D_{B} \\
\text { Backbone }\end{array}$ \\
\hline $32-42$ & -0.28 & 0.12 & -0.40 & 0.50 & 0.78 & 0.70 & 0.59 & 0.42 & 0.82 \\
$43-47$ & -0.60 & -0.61 & -0.60 & 0.45 & 1.05 & 0.60 & 1.22 & 0.43 & 1.03 \\
$58-68$ & -0.15 & 0.10 & -0.23 & 0.74 & 0.89 & 0.89 & 0.79 & 0.69 & 0.92 \\
$72-81$ & -0.34 & -0.21 & -0.39 & 0.51 & 0.85 & 0.73 & 0.95 & 0.44 & 0.83 \\
$83-85$ & -0.41 & -0.14 & -0.46 & 1.19 & 1.60 & 2.00 & 2.15 & 1.08 & 1.54 \\
$99-107$ & -0.48 & -0.31 & -0.52 & 0.45 & 0.93 & 0.56 & 0.87 & 0.42 & 0.94 \\
$112-134$ & -0.14 & 0.09 & -0.25 & 0.54 & 0.68 & 0.64 & 0.55 & 0.49 & 0.74 \\
$137-142$ & -0.34 & 0.07 & -0.42 & 0.64 & 0.98 & 1.27 & 1.20 & 0.53 & 0.95 \\
$144-153$ & -0.27 & 0.04 & -0.35 & 0.55 & 0.83 & 0.70 & 0.67 & 0.51 & 0.86 \\
\hline
\end{tabular}

$D_{R M S D}=R M S D_{A}-R M S D_{B}$, where $R M S D_{A}$ and $R M S D_{B}$ are RMSDs of a particular structure from the canonical A- and B-forms, respectively. Structures in the A-form half of 2D RMSD space have negative $D_{R M S D}$ values, and structures in the B-form half have positive $D_{R M S D}$ values. All RMSD values are calculated after a Kabsch least squared fit ${ }^{8}$ of the two structures using either all non-hydrogen atoms (All), or using only the non-hydrogen atoms of its base moieties (Base), or using only the non-hydrogen atoms of its sugar-phosphate backbone (Backbone). All RMSD values are normalized by the corresponding difference in RMSD between the canonical A- and B-form reference structures. 


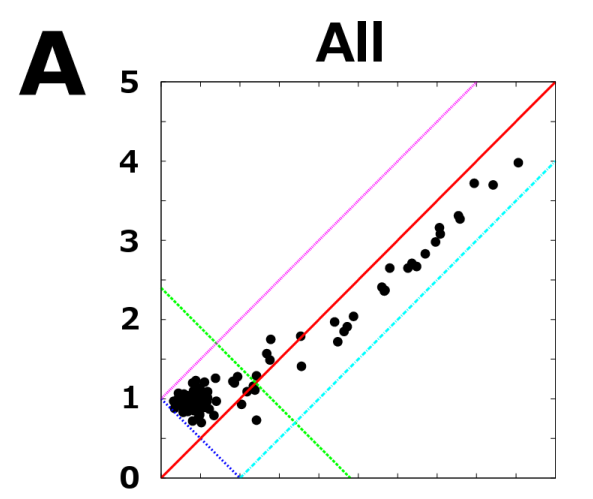

B
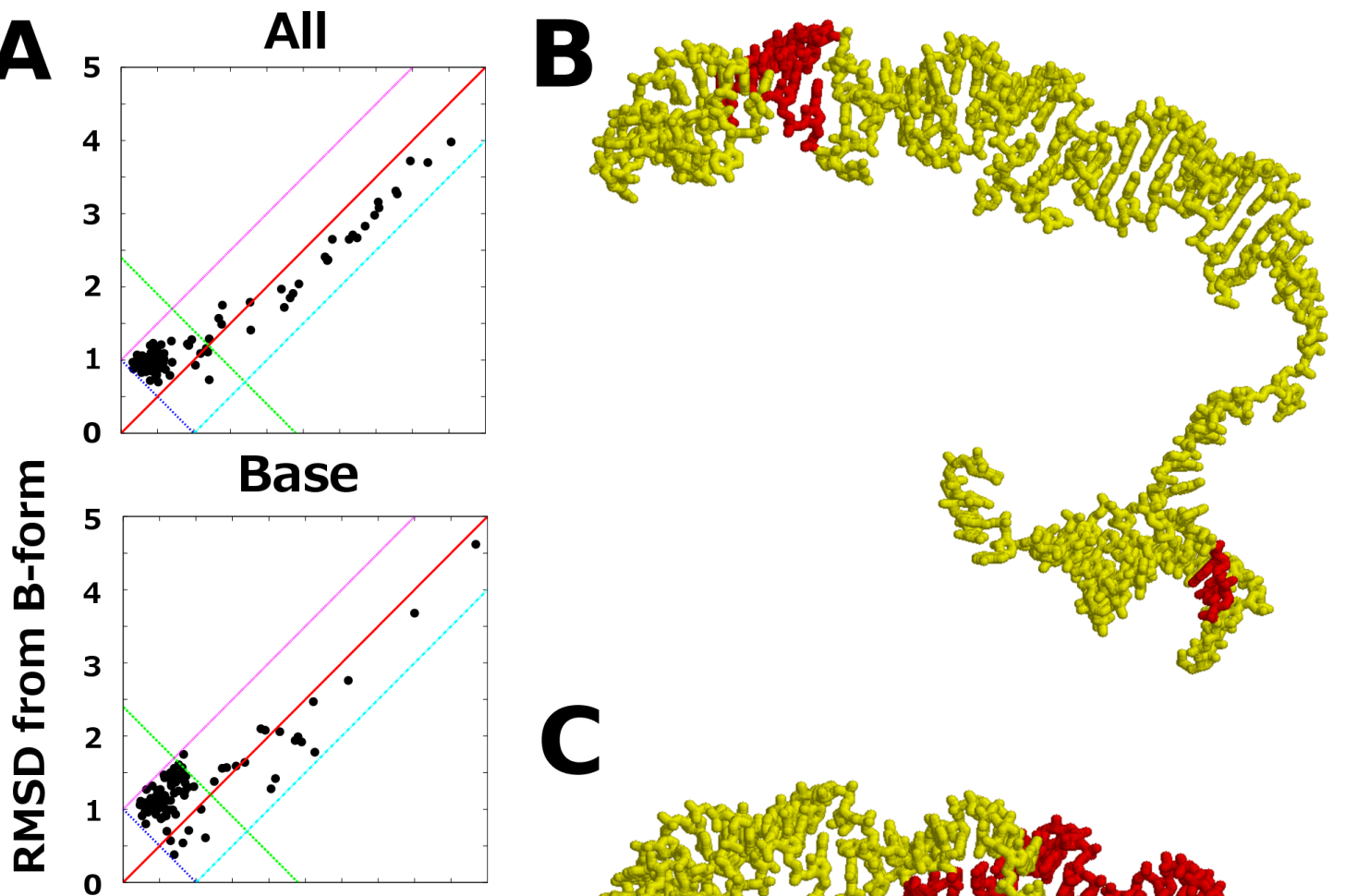

\section{Backbone}

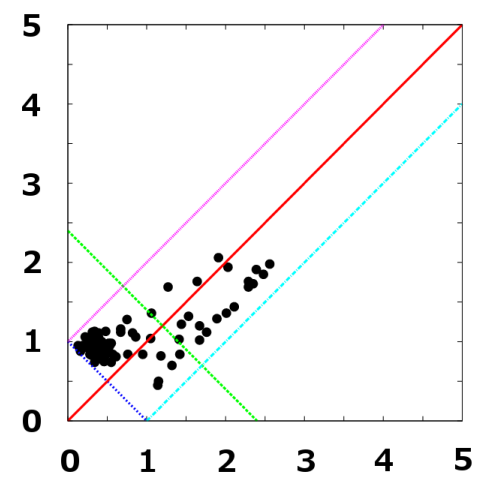

RMSD from A-form

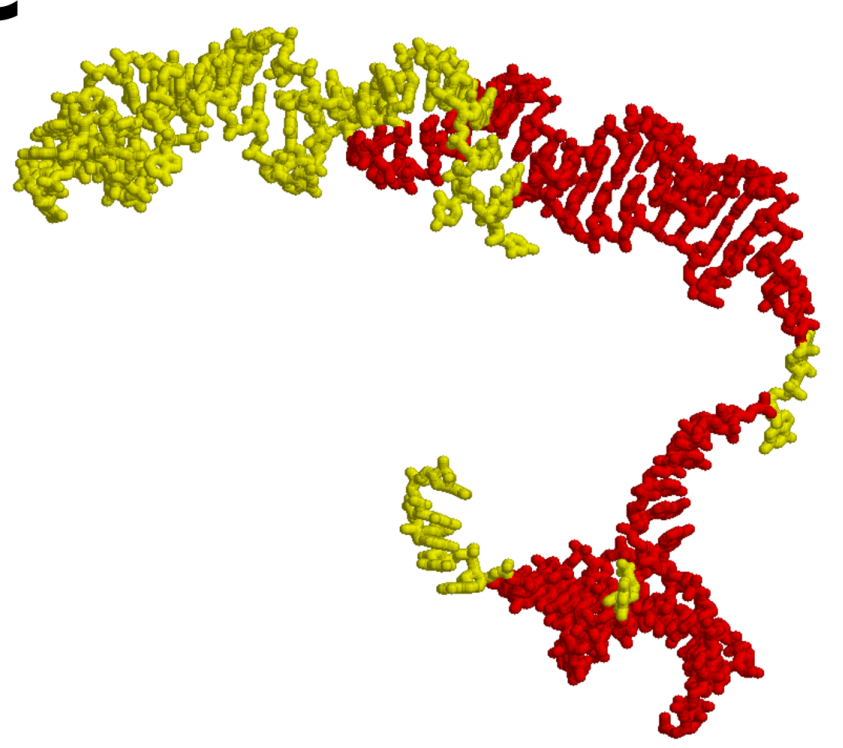

Figure 1: Analysis of SSD and longer RNA single strand B-form conformations in the 6S RNA variant structure bound to the E. coli RNA polymerase. (A) SSD conformations scatter plots for all SSD nonhydrogen atoms (top), base SSD non-hydrogen atoms (center), and sugar-phosphate backbone SSD nonhydrogen atoms (bottom) in normalized 2D RMSD space from the canonical A-form and B-form structures. The interpolation line between the two canonical forms is in dotted blue, the dividing line between A- and B-form regions is in solid red, the B-form region border is in dotted cyan, and the A-form region border is in dotted pink. (B) Structural location of SSDs (red) near the canonical B-form structure, as judged by presence in the B-form half and an additional cutoff of 1.0 in the perpendicular distance from the dotted blue interpolation line. (C) Indication of overall B-form segments (red) of extended stacked single strand regions of the 6S RNA structure according to base non-hydrogen atom RMSD values. 